\title{
Salud Mental en Atención Primaria: taller de herramientas de enfoque familiar
}

\author{
Mental Health in Primary Care: weaving family approach tools
}

\author{
Saúde Mental na Atenção Primária: tecendo ferramentas de abordagem \\ familiar
}

\section{Erika Vanessa Serejo Costa ${ }^{1}$, Marta Celia Cunha ${ }^{2}$, Marta Evelin de Carvalho ${ }^{3}$, Jardel Alcântara Negreiros ${ }^{4}$, Eliany Nazaré Oliveira ${ }^{5}$, Francisco Rosemiro Guimarães Ximenes Neto ${ }^{6}$}

\author{
${ }^{1}$ Cirurgiã-dentista. Mestre em Saúde da Família pela Universidade Estadual Vale do Acaraú \\ (UVA)/RENASF/FIOCRUZ. Correo electrónico: erikaserejo@hotmail.com. \\ ${ }^{2}$ Enfermeira. Mestre em Saúde da Família pela Universidade Estadual Vale do Acaraú \\ (UVA)/RENASF/FIOCRUZ. Correo electrónico: martaceliac@gmail.com. \\ ${ }^{3}$ Terapeuta Ocupacional. Mestre em Saúde da Família pela Universidade Estadual Vale do Acaraú \\ (UVA)/ RENASF/FIOCRUZ. Correo electrónico: martaevelin.pi@hotmail.com. \\ ${ }^{4}$ Enfermeiro. Mestrando em Saúde da Família pela Universidade Estadual Vale do Acaraú (UVA)/ \\ RENASF/FIOCRUZ. Correo electrónico: jardelnegreiros@gmail.com \\ ${ }^{5}$ Enfermeira. Pós-Doutorado em Psicologia pela Universidade do Porto. Docente do Curso de \\ Enfermagem e do Mestrado Profissional em Saúde da Família Universidade da Estadual Vale do Acaraú \\ (UVA). Correo electrónico: elianyy@hotmail.com. \\ ${ }^{6}$ Enfermeiro.Doutor em Ciências pela Universidade federal de São Paulo (UNIFESP). Docente do Curso \\ de Enfermagem e do Mestrado Profissional em Saúde da Família Universidade da Estadual Vale do \\ Acaraú (UVA). Correo electrónico: rosemironeto@gmail.com.

\begin{abstract}
Cómo citar este artículo en edición digital: Serejo Costa, E.V., Cunha, M.C.,Carvalho, M.E., Alcântara Negreiros, J., Nazaré Oliveira, E., \& Guimarães Ximenes Neto, F.R. (2018). Salud Mental en Atención Primaria: taller de herramientas de enfoque familiar. Cultura de los Cuidados (Edición digital), 22(51). Recuperado de <http://dx.doi.org/10.14198/cuid.2018.51.15>

Correspondencia: Universidade Estadual Vale do Acaraú - UVA - Av. da Universidade, 850 - Campus da Betânia - Sobral-CECEP: 62.040-370 Correo electrónico: erikaserejo@hotmail.com Recibido: 18/10/2017; Aceptado: 1/03/2018.
\end{abstract}

\section{ABSTRACT}

The objective of this case study is to conduct analysis of the relations of individuals with mental disorders, with the use of family approach tools in the municipality of Tianguá Ceará, Brazil, from April to June 2015. The information was collected through interviews and field diary, during home visits; followed by mapping and analysis of family assessment tools: typology, genogram, ecomap and
P.R.A.C.T.I.C.E. The family composition consists of four members, Rosa had hearing

impaired (mother and provider of the family) and three children had mental disorders: Carnation (Schizophrenia), Sunflower (severe mental disorder) and Margaret (mentally handicapped). This family lives in extreme social vulnerability according to the CoelhoSavassi Family Risk Scale (ERF-CS). The results showed a female single parent arrangement, scoring 32 at ERF-CS with frail social interaction and distant family relations, marked by mental decompensation and lack of 
specialized multidisciplinary support. The study shows the importance of using family approach tools to enhance practices and strengthen the role of the FHS/PHC. However, in view of complex cases alone, the FHS/PHC cannot be effective, requiring, therefore, matrix support of specialized network which provides more autonomy to the subjects.

Keywords: Primary Health Care; Mental Health; Comprehensive Health Care; Family Relations.

\section{RESUMEN}

Este estudio de caso tiene como objetivo realizar análisis de las relaciones de los sujetos con trastorno mental, a partir de herramientas de abordaje familiar, en el municipio de Tianguá Ceará, Brasil, en el período de abril a junio de 2015. Las informaciones fueron recolectadas por medio de una entrevista y diario de campo, durante visita al hogar, también mapeadas y analizadas a partir de las siguientes herramientas de evaluación familiar: tipología, genograma, ecomapa y P.R.A.C.T.I.C.E. El núcleo familiar está compuesto por cuatro miembros, siendo Rosa una deficiente auditiva (madre y proveedora de la familia) y tres hijos con trastorno mental: Clavel (esquizofrenia), Girasol (trastorno mental severo) y Margarita (deficiente mental), que viven en situación de extrema vulnerabilidad social, según la Escala de Riesgo Familiar Coelho-Savassi (ERF-CS). Los resultados evidenciaron un núcleo monoparental femenino, escore 32 de la ERF-CS, con interacción social frágil y relaciones familiares conflictivas y distantes, acentuadas por la descompensación mental y falta de apoyo multiprofesional especializado. El estudio muestra la importancia del uso de herramientas de abordaje familiar para potenciar prácticas y fortalecer el papel ordenador de la ESF/APS. Sin embargo, delante de casos complejos, solamente, la ESF/APS no consigue hacer efectiva la integralidad, requiriendo, por lo tanto, apoyo matricial de la red especializada, proporcionando más autonomía a los sujetos.

Palabras clave: Atención Primaria a la Salud; Salud Mental; Asistencia Integral a la Salud; Relaciones Familiares.

\section{RESUMO}

Este estudo de caso objetiva realizar análise das relações dos sujeitos com transtorno mental, a partir de ferramentas de abordagem familiar, no município de Tianguá - Ceará, Brasil, no período de abril a junho de 2015. As informações foram coletadas por meio de uma entrevista e diário de campo, durante visita ao lar, também mapeadas e analisadas a partir das seguintes ferramentas de avaliação familiar: tipologia, genograma, ecomapa e P.R.A.C.T.I.C.E. O núcleo familiar é composto por quatro membros, sendo Rosa uma deficiente auditiva (mãe e provedora da família) e três filhos com transtorno mental: o Cravo (esquizofrenia), o Girassol (transtorno mental severo) e a Margarida (deficiente mental), que vivem em situação de extrema vulnerabilidade social, segundo a Escala de Risco Familiar Coelho-Savassi (ERF-CS). Os resultados evidenciaram um arranjo monoparental feminino, escore 32 da ERF-CS, com interação social frágil e relações familiares conflituosas e distantes, acentuadas pela descompensação mental e falta de apoio multiprofissional especializado. O estudo mostra a importância do uso de ferramentas de abordagem familiar para potencializar práticas e fortalecer o papel ordenador da ESF/APS. Contudo, diante de casos complexos, sozinha, a ESF/APS não consegue efetivar a integralidade, requerendo, portanto, apoio matricial da rede especializada, proporcionando mais autonomia aos sujeitos.

Palavras chave: Atenção Primária à Saúde; Saúde Mental; Assistência Integral à Saúde; Relações Familiares.

\section{INTRODUÇÃO}

A Saúde Mental e a Atenção Primária à Saúde (APS) são campos que convergem a um propósito comum, que é a melhoria da qualidade de vida das famílias, sujeitos e comunidades. No caso do Brasil, a Estratégia Saúde da Família (ESF), eixo estruturante da APS, concebe a família de modo integral e sistêmico, como espaço de produção social, dinâmico e passível de crises, sendo ao mesmo tempo, objeto e sujeito do processo de cuidado e de promoção da saúde dos trabalhadores da saúde (Brasil, 2013). Para Carvalho (2015) a importância da família é inquestionável na ajuda ao seu processo de tratamento, cura e reabilitação, pelo que deve ser 
um elo, uma verdadeira parceira dos cuidadores, e em particular na área da saúde mental, tem de ser potencializada para exercer esta função. A família do sujeito com transtorno mental, apresenta-se inserida em um cenário de sofrimento psíquico e subjetivo, que atinge todos os seus membros. Este sofrimento se manifesta de formas diferentes em cada família e seus membros; no entanto, em todas elas, é capaz de deixar marcas profundas que podem se tornar irreparáveis. Nesse aspecto, torna-se clara a necessidade de se intervir não apenas com um plano de cuidados ao sujeito com transtorno mental, mas com sua família, que o assiste e sofre junto, levando em consideração que esta também está sujeita ao adoecimento (Oliveira et al., 2014).

Com isso, a ESF/APS ao assumir seu papel de prover a atenção integral à saúde, é também uma importante política para trabalhar a saúde mental na comunidade - incluindo o tratamento dos transtornos mentais, dentre outros; que por meio de seus fundamentos e princípios pode identificar e avaliar as principais dificuldades e fatores estressores no espaço familiar e comunitário, além de propiciar um seguimento mais próximo do usuário, de sua família e da comunidade em que este está inserido (Binotto et al., 2012). Contudo, inovadores dispositivos de tratamento e reabilitação podem ser utilizados, suscitando novas práticas e saberes a serem apropriados pelos trabalhadores da saúde para desenvolverem melhores práticas de cuidado, na busca da reabilitação psicossocial e promoção da cidadania plena do doente mental e de sua família (Correia, Barros \& Colvero, 2011). Por isso, este estudo de caso tem como objetivo realizar análise das relações de sujeitos com transtorno mental, a partir de ferramentas de abordagem familiar.

\section{METODOLOGIA}

\section{Tipologia, Cenário e Sujeitos do Estudo}

Artigo desenvolvido a partir de um estudo de caso, tendo como unidade de análise uma família de uma senhora e três membros com transtorno mental, de Tianguá - Ceará, Brasil, durante o período de abril a junho de 2015. O estudo de caso utilizou o referencial de Yin (2001, p. 26), que segundo o autor busca explicar os vínculos causais em intervenções da vida real que são complexas demais para as estratégias experimentais. A família em estudo pertence ao território da ESF da Unidade de Saúde da Família (USF) do bairro Governador Ferraz, área descoberta do acompanhamento do Agente Comunitário de Saúde (ACS). Após inquérito verbal com a equipe da referida USF acerca das famílias mais vulneráveis socialmente existentes na área desassistida, foi efetuada visita ao lar de uma das famílias, a qual considerou-se de extrema necessidade de intervenção e elaboração de um plano de cuidados com base em um projeto terapêutico singular.

\section{Técnicas e Instrumentos}

Para avaliação da família em estudo foi utilizada a Escala de Risco Familiar de CoelhoSavassi (ERF- CS) que é um instrumento para estratificação de risco aplicado às famílias adscritas a uma equipe de saúde, utilizando, para tanto, informações presentes na "Ficha A" do Sistema de Informação da Atenção Básica (SIAB) definidas como "sentinelas de risco", cuja soma dos escores de risco de cada família, as classificam em risco menor a máximo (Savassi, Lage \& Coelho, 2012), conforme Quadro 1 a seguir:

\begin{tabular}{|l|c|}
\hline Escore total & Risco Familiar \\
\hline 5 e 6 & R1 - risc o menor \\
\hline 7 e 8 & R2 - risc o médio \\
\hline Ac ima de 9 & R3 - risc o má ximo \\
\hline \multicolumn{2}{|c|}{ Quadro 1. Escores de Risco da Escala de Risco Familiar } \\
Coolho-Savassi. \\
Fonte: Savassi, L.C.M., Lage, J.L. \& Coelho, \\
F.L.G. (2012). Sistematização de um instrumento de \\
estratificação de risco familiar: escala de risco familiar \\
Coelho-Savassi. Journal of Management and Primary Health \\
Care, 3(2), 179-185
\end{tabular}

As informações foram coletadas por meio da visita ao lar, utilizando-se a observação e anotações em diário de campo, com perguntas direcionadas a filha cuidadora, mas não residente na casa, e ao sujeito índice da família (Rosa).

Com as novas abordagens em saúde mental, as famílias de doentes mentais necessitam de um maior contato com os serviços próprios especializados, e estes por sua vez precisam de ferramentas e estratégias para 
produção do cuidado de forma eficaz. Segundo Carvalho (2015) as famílias de sujeitos com transtornos mentais necessitam ser envolvidas no cuidado, tornando-se ativas e responsáveis por este tratamento e possível reabilitação. Para tanto, foram utilizadas as seguintes ferramentas de abordagem familiar utilizadas: Tipologia Familiar, Genograma, Ecomapa e P.R.A.C.T.I.C.E..

\section{Tipologia Familiar}

Admitindo o conceito de família como sendo o núcleo básico da sociedade, a classificação mais utilizada pelos estudos de psicologia e sociologia para a tipologia é a de Kaslow de composição familiar, que consiste no arranjo dos membros que compõem a família em: nuclear, extensiva, adotivas, casais, monoparentais, homoafetivas, reconstituídas ou convivência mútua sem laços legais (Carnut \& Faquim, 2014).

\section{Genograma e Ecomapa}

A dinâmica da vida familiar deve ser avaliada com respeito e valorização das características peculiares e do convívio humano. O genograma e o ecomapa constituem instrumentos de registro familiar, que segundo o Caderno de Atenção Domiciliar do Ministério da Saúde, o genograma permite identificar, de maneira mais rápida tal dinâmica familiar e suas possíveis implicações, mostrando graficamente a estrutura e o padrão de repetição das relações familiares, bem como as repetições de padrões de doenças, relacionamento e os conflitos resultantes do adoecer, reunindo informações também sobre a rede de apoio psicossocial, os antecedentes genéticos, as causas de óbitos de membros da família, além dos aspectos psicossociais apresentados junto com as informações coletadas na anamnese (Brasil, 2012). Acrescenta-se ainda, os símbolos representativos sobre a estrutura familiar, os dados demográficos, a história clínica e as relações entre os elementos de uma família, por pelo menos três gerações (Santos, 2012).

Complementar ao genograma, o ecomapa consiste na representação gráfica dos contatos dos membros da família com os outros sistemas sociais, das relações entre a família e a comunidade, entre outros; colaborando na avaliação dos apoios e suportes disponíveis e sua utilização pela família e pode apontar a presença de recursos, sendo o retrato de um determinado momento da vida dos membros da família, portanto, dinâmico (Brasil, 2012).

\section{- P.R.A.C.T.I.C.E.}

A avaliação familiar é facilitada pelo desenvolvimento do esquema P.R.A.C.T.I.C.E. que opera por momentos durante a entrevista familiar, fornecendo as informações sobre que intervenções podem ser utilizadas para manejar situações mais difíceis, focado na resolução de problemas (Ditterich, Gabardo \& Moysés, 2009). Tal ferramenta organiza as informações obtidas com a família e facilita sua avaliação, ajudando o profissional a lidar com os problemas familiares (Santos et al., 2015). O esquema P.R.A.C.T.I.C.E. nasce das seguintes palavras originárias do inglês: P (Presenting Problem Problema apresentado ou razão da entrevista); $\mathrm{R}$ (Roles ad Structure - Papéis e estrutura); A (Affect - Afeto); C (Communication Comunicação); T (Time in the family life cycle Tempo no ciclo de vida familiar); I (Illness in family past and present - Enfermidade na família no passado e no presente); C (Coping with Stress - Enfrentando o estresse) e E (Ecology Ecologia) (Silveira Filho, Ducci, Simão, Moysés, \& Gevared, 2002).

\section{Aspectos Éticos e Legais do Estudo}

Durante o desenvolvimento do estudo, foram observados os aspectos éticos e legais da pesquisa de acordo com a Resolução $N^{\circ}$ 466/2012 do Conselho Nacional de Saúde (CNS), preservando a ética dos sujeitos envolvidos, cujas informações são restritamente relacionadas às experiências vivenciadas, resguardando o sigilo de nome, para o qual adotou-se nomes fictícios de flores. A cuidadoratutora legal autorizou a participação dos familiares por meio da assinatura do Termo de Consentimento Livre e Esclarecido (TCLE).

\section{APRESENTAÇÃO E DISCUSSÃO DO CASO}

\section{Caso Clínico}


A família abordada mora em casa sustentada por barro e madeira, circundada por becos e esgotos, cuja vizinhança é repleta do cultivo de flores, o que nos chamou atenção pelo contraste imenso que provoca frente situação vivida pelos integrantes da residência da família em estudo. A família relata que reside há 15 anos no bairro, mas nunca frequentou a unidade de saúde local, fato que surpreendeu a equipe de APS durante a abordagem, pelo seu desconhecimento acerca da existência e da problemática desta.

O núcleo familiar é composto por quatro membros, sendo Rosa uma senhora deficiente auditiva (mãe e provedora da família) e três filhos com transtornos mentais: o Cravo (esquizofrenia), o Girassol (transtorno mental severo, sem diagnóstico psiquiátrico) e a Margarida (deficiência mental). A renda familiar advém dos proventos da Seguridade Social da pensão da de Margarida e da aposentadoria de Rosa. A tutora legal, Gardênia, é uma filha que mora próximo a qual recebe e administra os proventos, bem como cuida das necessidades básicas de sua família.

Rosa, é uma viúva de 69 anos, com atividade ocupacional por toda a vida na agricultura, sendo a genitora e sujeito-índice desse estudo. Há cerca de dois anos, quando havia agente de saúde na área, foi consultada pela médica da USF, cujos exames socitados e coletados no próprio lar, evidenciaram a glicemia elevada (385 mg/dl). Rosa convive com três dos últimos filhos, de uma prole de 10 filhos; são eles: Cravo (38 anos), Girassol (37 anos) e Margarida (27 anos). Outras três filhas moram na vizinhança, dois faleceram ainda na infância e há outro que reside em outro município.

A idade dos filhos do núcleo familiar é incerta, pois as informações ditas por estes não são seguras, visto não haver documentos de identidade e nem registro de nascimento, os quais foram rasgados por Cravo, o mais velho do trio e com esquizofrenia; que segundo relatos da mãe, não toma banho há mais de dois anos nem sequer sai do quarto, cujo assoalho é recoberto por fezes e urina.

Girassol já teve filhos e esposa, era alcoolista e teve tempos que andava como andarilho nas estradas, comendo restos de comida do lixo, até que sua irmã mais velha (Gardênia) o encontrou e o levou para casa. Atualmente, Girassol não está sob nenhum tratamento medicamentoso e tem o hábito de tomar banho de cinco em cinco minutos, com a roupa do corpo, referindo um calor frequente que só alivia com água. Não sai de casa, por sentir medo, que provoca palpitações. Margarida nasceu com deficiência mental e vive restrita ao leito, não verbaliza palavras, é fumante e gosta de ouvir rádio.

\section{Ferramentas de Avaliação Familiar}

O grande desafio do atendimento familiar em saúde mental é fazer com que esse cuidado não se torne um fardo, e sim, que a família tenha condições de desenvolver seu papel de maneira eficaz, sem lhe trazer prejuízos, colaborando com o tratamento do familiar portador do transtorno (Oliveira et al., 2014). Contudo, ferramentas de acompanhamento e monitoramento são em geral um bom caminho para a atenção à saúde mental. Neste estudo de caso foram utilizadas ferramentas abordagem familiar (escala de avaliação de risco, tipologia familiar, genograma, ecomapa e P.R.A.C.T.I.C.E.), com o intento de buscar elementos de suporte e análise, que permitam a identificação assertiva dos problemas, com possibilidades efetivas de intervenção.

Portanto, na análise do processo saúdedoença-cuidado, a avaliação funcional da família permite compreender a função de cada membro em seu contexto e as atividades da vida diária prejudicadas por alguns determinantes e condicionantes sociais e sanitários (Nascimento, Ximenes Neto, Saburido \& Chagas, 2012).

\section{Escala Coelho-Savassi}

Em estudo realizado no estado do Paraná - Brasil, utilizando a escala de Savassi, concluiu que a aplicação desta para a estratificação de risco, permite direcionar as ações mediante critérios definidos e determinar a frequência das visitas aos lares pelos diferentes profissionais da saúde que atuam na ESF/APS, priorizando as famílias de risco máximo de vulnerabilidade (R3), as quais deverão ser assistidas com mais atenção e cujo acompanhamento deverá ocorrer em intervalos mais curtos que o das outras famílias (Menezes et al., 2012).

A aplicação da escala de risco proposta por Savassi et al., (2012) permitiu identificar a 
situação de extrema vulnerabilidade da família, totalizando um escore no valor 32, evidenciando circunstância de risco máximo de vulnerabilidade social (R3), conforme apresentado no Quadro 2.

\begin{tabular}{|l|l|}
\hline \multicolumn{1}{|c|}{$\begin{array}{c}\text { Dados da Ficha A do } \\
\text { SIAB da Família }\end{array}$} & Escores \\
\hline Acamado & 0 \\
\hline Deficiência Física & 0 \\
\hline Deficiência Mental & $3+3+3=9$ \\
\hline Baixas condições sanitárias & 3 \\
\hline Desnutrição grave & 0 \\
\hline Drogadição & $2+2+2=6$ \\
\hline Desemprego & $2+2+2=6$ \\
\hline Analfabetismo & $1+1+1+1=4$ \\
\hline $\begin{array}{l}\text { Indivíduo menor de seis meses } \\
\text { de idade }\end{array}$ & 0 \\
\hline $\begin{array}{l}\text { Indivíduo maior de 70 anos de } \\
\text { idade }\end{array}$ & 0 \\
\hline Hipertensão Arterial Sistêmica & 0 \\
\hline Diabetes mellitus & 1 \\
\hline $\begin{array}{l}\text { Relação morador/ cômodo maior } \\
\text { que } 1\end{array}$ & 0 \\
\hline $\begin{array}{l}\text { Relação morador/cômodo igual a } \\
1\end{array}$ & 3 \\
\hline $\begin{array}{l}\text { Relação morador/cômodo menor } \\
\text { que } 1\end{array}$ & 0 \\
\hline \multicolumn{1}{|c|}{ Total de escores } & $\mathbf{3 2}$ \\
\hline
\end{tabular}

Quadro 2. Escore de risco da família abordada no estudo. de estratificação de risco familiar: escala de risco familiar Coelho-Savassi. Journal of Management and Primary Health Care, 3(2), 179-185

Fonte: Savassi, L.C.M., Lage, J.L. \& Coelho, F.L.G. (2012). Sistematização de um instrumento

Dentro de uma perspectiva ampliada, em busca da tão necessária promoção de saúde, os profissionais da ESF/APS devem saber lidar com as diversas condições socioeconômicas, marcada simultaneamente pelos diversos determinantes sociais da saúde, tais como a falta de emprego, de uma infraestrutura adequada água potável, destino adequado do lixo e esgoto, poluição, carência nutricional e déficit do conhecimento e educacional, e até mesmo opostos estilos de vida, buscando não somente aproximar-se mas também transcender de modo corresponsável, tais determinantes (Spagnuolo \& Guerrini, 2005). Diante da constatação do risco, para a abordagem da família, preliminarmente a equipe esboçou um plano de trabalho, esclarecendo e compreendendo o tipo de abordagem e os instrumentos que melhor assegurassem sua privacidade e conquistasse a confiança a ser buscada entre membros familiares-pesquisadores.

\section{As ferramentas de Abordagem Familiar utilizadas}

\section{Genograma}

Como um mapa, O genograma pode ser utilizado pelos terapeutas familiares nas diferentes modalidades de atendimento, ou seja, individual, casal, família; em diversos contextos: clínico/ambulatorial, hospitalar; e de diversas formas: desenhado junto com os clientes na sessão, feito apenas pelo terapeuta após o atendimento. Porém, esta última limita as conexões que o terapeuta pode fazer junto com a família, casal ou individualmente e deixa de propiciar aos mesmos os insights que podem trazer a investigação da história familiar por meio deste (Barreto, 2010). 
O esquema para descrição do genograma embasou-se nos relatos de Gardênia, cuidadora e tutora da família, haja visto a progenitora ser deficiente auditiva e não compreender os questionamentos realizados durante a abordagem familiar, bem como os demais membros familiares não se comunicarem efetivamente devido as sequelas provocadas pelo processo de adoecimento e vulnerabilidade social.

Gardênia refere que seus pais tiveram uma prole de 10 filhos, sendo seis do sexo masculino. Destes, dois foram a óbito ainda na infância por motivos desconhecidos. O cônjuge de Rosa era agricultor e foi a óbito por cirrose hepática alcóolica. Segundo Gardênia, a surdez de sua mãe surgiu logo após a gestação da décima filha, Margarida e que em visita ao lar realizada pela médica da ESF, há alguns anos, foi diagnosticada com diabetes mellitus. Margarida, vive abstraída, em grande parte do dia imóvel, apenas fumando cigarro de tabaco e ouvindo rádio.
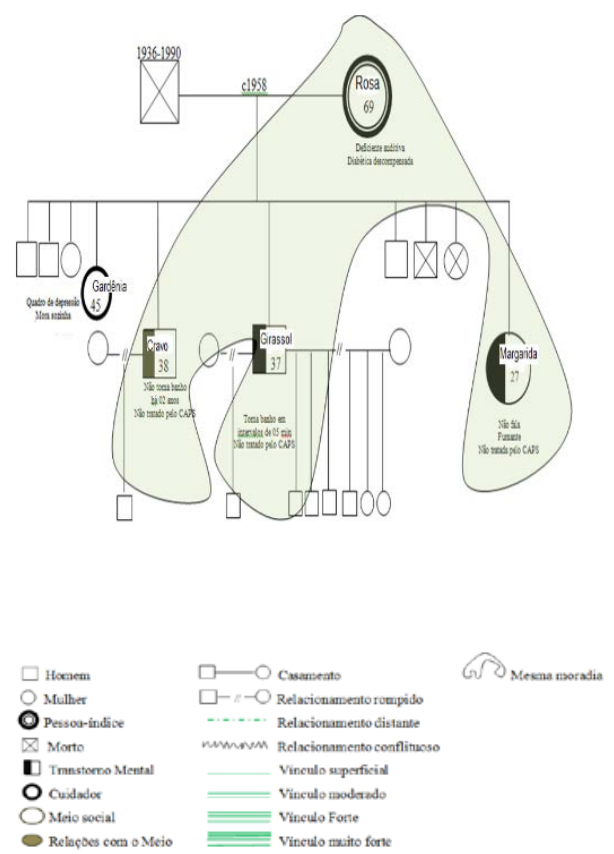

Figura 1. Genograma da Família de Rosa.

Gardênia relata que parentes próximos de Rosa (Figura 1) eram sujeitos que sofriam com doenças mentais, e que não estranhava o fato de seus três irmãos, apresentarem a doença. Ela mesma relatou tratar-se de depressão. Os relacionamentos dos membros do núcleo familiar são bastante distantes e por vezes conflituosos, visto que Rosa não escuta e por este motivo pouco fala; vive segurando um chicote feito de palha de bananeira para ter controle das crises psicóticas de Cravo. Este, sendo muito agressivo, vive dentro de um quarto no fundo da casa, nunca saindo, e fazendo neste espaço todas suas necessidades fisiológicas há mais de dois anos. Ele tem um filho de um relacionamento casual. Apenas Girassol esboça algum tipo de comunicação quando terceiros visitam a casa, mas de modo confuso e desconexo. Girassol tem sete filhos oriundo de dois relacionamentos diferentes.

Em estudo realizado no estado de Minas Gerais - Brasil constatou que a aplicação do genograma e do ecomapa permite um aprofundamento do conhecimento da família como um todo e da dinâmica de funcionamento familiar à medida que propicia o levantamento de informações para um conhecimento inicial da família. Contudo, o uso desse instrumento não se basta, quando se pretende intervir, fazendo-se necessário a aplicação de outras ferramentas de acesso à família para continuidade da análise e estabelecimento de um projeto terapêutico singular para os sujeitos do estudo (Vieira, Ferreira, Araújo, Vieira \& Rodrigues 2014), tais como o ecomapa que sistematiza os pontos da rede social familiar.

\section{Ecomapa}

Como a representação da rede social da família e das relações intrafamiliares, o ecomapa esquematiza como funciona a relação desta com o meio social, os vínculos bem como a atuação de diferentes serviços de saúde junto ao caso (Santos et al., 2015) (Figura 2). Buscar uma intervenção baseada na abordagem sistêmica do cuidado à família, o ecomapa denuncia a vínculos/tensões e/ou ausências entre a estrutura da família e seu meio social, possibilitando uma visão essencial para que a equipe assuma uma postura de gestão que naturalmente indicia o comando do processo do planejamento do plano de cuidados (Santos, 2012).

Gardênia refere ser o único elo da família com o meio externo, haja vista que sua mãe e seus irmãos não saírem de casa. Há consenso entre eles não de abrirem as janelas, pois não gostam da claridade do sol, tão pouco de contanto com a vizinhança da rua em que moram. Girassol relata 
que sente medo e palpitações quando pensa em sair de casa e que, devido a um calor constante, toma banho em um banheiro externo da casa de cinco em cinco minutos. Gardênia recebe os benefícios sociais da família e cuida das necessidades básicas desta. Menciona que nunca frequentou a USF, e não soube explicar como faz para conseguir a única medicação de uso controlado que traz para os irmãos.

Figura 2. Ecomapa da Família de Rosa

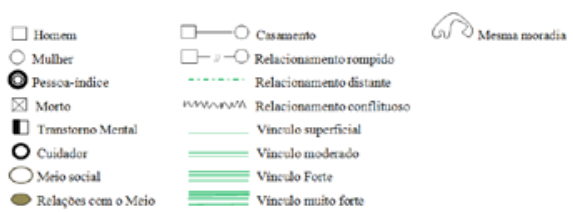

\section{Tipologia Familiar}

A família deste estudo é monoparental feminina, em que Rosa é viúva, progenitora e provedora do núcleo familiar, com três filhos em estado avançado de transtorno mental, extremamente dependentes dos cuidados, ainda que limitados, da mesma. A família monoparental feminina é aquela em que vivem juntos mãe e filho, ou filhos, nas qual a mulher é mãe solteira, divorciada/separada ou viúva que não mais quis ou teve a oportunidade de uma união estável. A realidade de mulheres em situação de vulnerabilidade social é permeada por contradições que afirmam sua complexidade, ao longo da história brasileira. A maternidade e a relação parental são dimensões significativas da identidade feminina e do sentido da vida, e as impulsionam ao trabalho, ao sustento do lar, à batalha de cada dia, à superação de desafios. Há que qualificar as possibilidades de enfrentamento e sobrevivência de mulheres brasileiras pobres chefes de famílias monoparentais, pois muitos são os fatores que interferem na vida dessas mulheres, sejam eles, fatores individuais, sociais, culturais ou relacionais (Costa \& Marra, 2013).

Um estudo realizado em Acaraú - Ceará, utilizando a tipologia familiar, constatou que esta classificação quanto ao tipo de família fornece conhecimentos não só sobre a estrutura familiar, mas também contribui para a compreensão da dinâmica familiar suas interrelações seus papéis e padrão de comunicação (Dutra, Vasconcelos, Teófilo \& Teófilo, 2012). Nesse estudo, embora com restrições de comunicação, a idosa e progenitora exerce papel dominante no núcleo familiar, não só por realizar os serviços próprios do lar, mas por manter a ordem familiar e o controle das crises psicóticas dos filhos, ainda que com o uso coercitivo de seu chicote de palha. Entretanto, para além de conhecer a estrutura e dinâmica familiar, para um planejamento do plano de cuidados, a exemplo de um projeto terapêutico singular, sucumbe também a necessidade de 
identificação dos principais problemas, dos papeis, dos afetos, do padrão de comunicação dentre outros aspectos e, para tanto, foi utilizada a ferramenta P.R.A.C.T.I.C.E..

\section{P.R.A.C.T.I.C.E.}

No acrônimo $\mathbf{P}$ (principal problema), como problema foi identificado a ausência de familiar como provedor dos cuidados de saúde e o agravo dos transtornos mentais existentes. Considerando este aspecto, percebe-se que os sujeitos com transtornos mentais, infelizmente já são cotidianamente estigmatizados na sociedade atual. Em famílias pobres, o isolamento é agravado, pois a questão financeira reforça a visão do portador de transtorno mental como mais um "gasto" não-desejado (Carnut \& Faquim, 2014). Estudo mostra que a APS realiza a maioria dos atendimentos psiquiátricos, pois, mesmo nos países que mais investem em saúde mental, existe uma lacuna entre a oferta e a demanda por serviços especializados. No Brasil, preconiza-se que a ESF/APS assista aos sujeitos com transtorno mental e o apoio matricial de uma equipe especializada é uma ferramenta para qualificar esse trabalho (Binotto et al., 2012). Contudo, no caso em estudo, a lacuna do problema se agiganta, quando o território, e, em particular a família vulnerável, por não estar inserida na rede de atenção à saúde.

Em $\mathbf{R}$ (papéis e estrutura), percebeu-se a mãe como única provedora de cuidados aos filhos, tendo suporte de dois filhos que moram próximo e que ajudam na retirada mensal do dinheiro da pensão e aposentadoria de Margarida, e na compra de alimentos. As tarefas domésticas ficam todas sob a responsabilidade da genitora, que esporadicamente recebe ajuda da filha deficiente mental.

Referente ao A (afeto), devido ao estupor depressivo da filha constatou-se a inexistência de afeto entre ela, a mãe e os outros irmãos. O primeiro filho pelo seu estado psicótico encontra-se em isolamento social, mostrando-se agressivo verbal e não apresentando nenhuma demonstração de afeto aos membros familiares. O afeto só é percebido de forma muito sutil entre o segundo filho e a mãe. O filho mais velho se mostra preocupado com a idade da mãe e a sobrecarga de trabalho, porém devido ao seu transtorno mental não consegue ajudá-la. Este também ainda interfere na relação da mãe com o outro irmão quando este a trata mal. A mãe demonstra afeto ao filho mais velho quando relata com satisfação e orgulho o quanto ele era trabalhador, mas, ao mesmo tempo, mostra medo do seu retorno a vida profissional porque pode deixá-lo mais vulnerável ao uso novamente de bebida alcoólica.

Em relação a $\mathbf{C}$ (comunicação), constatou-se a quase inexistência de comunicação verbal entre os familiares e uma dificuldade no diálogo familiar devido a deficiência auditiva da mãe, que devido esta condição, utiliza de métodos não verbais por meio do uso do chicote de palha e sinais. Os filhos entre si não se comunicam, exceto com Gardênia, que mantém verbalização breve e arredia, com os mesmos, em particular com Cravo.

Referente a $\mathbf{T}$ (tempo no ciclo de vida familiar), percebe-se a dificuldade de definir o ciclo de vida dessa família devido a presença de fatores estressores como: a morte do pai, que era o único provedor da família, o transtorno mental dos três filhos e a perda auditiva da mãe. Supõese que a etapa do ciclo de vida dos filhos adolescentes foi interrompida e pelos agravos citados impedida de realizar a transição para a etapa dos filhos que se emancipam.

No tópico I (enfermidade na família no passado e no presente), constatou-se que a atual provedora do lar apresenta deficiência auditiva e diabetes mellitus e que os três filhos possuem transtornos mentais. O isolamento social característico da família e o analfabetismo prejudica o tratamento de todos que não frequentam a unidade da saúde da ESF/APS e nem o Centro de Atenção Psicossocial (CAPS), não fazem uso correto da medicação e que só usam quando filha que mora próximo a leva. De um modo geral, as relações familiares entre dois membros da família, chamadas de diádicas, como por exemplo, pai-filho, mãe-filho ou a própria composição da família são responsáveis ou pela manutenção da saúde ou pelo adoecimento do sujeito em desenvolvimento (Carnut \& Faquim, 2014). Tanto o afeto quanto a comunicação verbal ou não verbal, interferem negativamente nos problemas familiares (Ditterich et al., 2009).

Quanto a C (enfrentando o estresse), observouse que grande parte do cuidado com a mãe e os irmãos fica sempre com uma das filhas que mora próximo e que também tem transtorno mental. Há uma sobrecarga de trabalho para mãe que é responsável pelo preparo da alimentação e organização da casa, devido a dependência dos filhos. Não há acesso aos recursos sociais da rede e nem apoio de vizinhos, pelo comportamento isolado da família. A sobrecarga do trabalho doméstico pode ser compreendida pelo fato da família ser monoparental feminina. Prover o sustento e cuidar da família é uma 
situação praticamente impossível nesta tipologia a não ser quando alguém ajude. Geralmente os vizinhos, ou parentes que moram perto para ajudar (Carnut \& Faquim, 2014), papel este exercido por Gardênia. Entretanto, a socialização dos membros, que na infância seria monopólio da mãe ou do cuidador, neste caso não ocorre, devido ao isolamento social e comunicativo oriundo das deficiências auditiva e mental da família.

Em E (ecologia), evidenciou-se a inexistência de família ampliada e a redução do apoio dos próprios familiares. Não há relacionamento social com amigos e vizinhos, os quais se opõem à permanência da família no território por residirem em um terreno que impede fluxo de pessoas e transporte nas redondezas. Gardênia é elo da família com o meio social, embora não resida com os mesmos.

\section{CONSIDERAÇÕES FINAIS}

$\begin{array}{lll}\text { A Reforma } & \text { Psiquiátrica Brasileira foi } \\ \text { responsável } & \text { pelo } & \text { processo de }\end{array}$
desinstitucionalização compulsória, impulsionando um novo cenário na atenção à saúde mental, cujos hospitais psiquiátricos deixam de constituir a base do sistema assistencial, cedendo a uma rede de serviços extra hospitalares de crescente complexidade a partir da APS. Quando necessária, a internação psiquiátrica acontece com períodos mais curtos de hospitalização, favorecendo a consolidação de um modelo de atenção à saúde mental integral, dinâmico, aberto e de base comunitária. Neste novo contexto, a família passa a ter importante papel no tratamento, recuperação e reabilitação.

Como parte da rede de atenção, a ESF/APS como ordenadora da produção do cuidado na comunidade, a articulação e ação integrada com os setores especializados em saúde mental devem constituir uma via de mão dupla. Assim, a experiência brasileira, em que a ESF/APS é o elo inicial da rede integral de saúde mental, têm evidenciado resultados significativos no cuidado às famílias de sujeitos com transtornos mentais, pois a Política de Saúde Mental, que orienta atualmente a Reforma Psiquiátrica, estimula ações pautadas no território, articuladas a uma rede ampliada de serviços de saúde a partir do lócus do sujeito.

Contudo, o estudo revelou que, diante de casos complexos, o cuidado e a assistência necessária para minimizar o avanço das doenças, quaisquer sejam, bem como promover saúde em situações de extrema vulnerabilidade social, ultrapassam largamente as atribuições da equipe de referência da ESF, sendo pungente apoios matriciais, envolvimento de outras disciplinas e outros setores, em busca de efetivar a integralidade da atenção e a longitudinalidade do cuidado. Além disso, percebeu-se também que territórios desassistidos da atuação do profissional ACS, prejudica demasiadamente a qualidade da atenção e, em consequência disto, inferindo nos princípios da universalidade, equidade e integralidade do Sistema Único de Saúde (SUS), à medida que a ESF/APS não consegue sequer ter conhecimento das vulnerabilidades sociais do território, quanto menos ordenar o cuidado na rede de atenção à saúde.

Portanto, o plano de cuidados baseou-se na intensificação de visitas ao lar pela equipe da ESF/APS, para a construção de vínculo com a família. O compartilhamento do caso com a equipe do CAPS e do Núcleo de Apoio à Saúde da Família será extremamente necessário para a construção de um projeto terapêutico singular, devendo estes serem corresponsáveis, dentre outros aspectos, junto à família: a reavaliação do psiquiatra aos sujeitos com transtorno mental; inserção dos sujeitos nos grupos terapêuticos para estimular a socialização; resgate da documentação; a orientação medicamentosa; e, a ressocialização da família. Além disto, a aplicação do inventário de habilidades de vida independente para os sujeitos com transtorno mental e o incentivo às ações de autocuidado também deverão ser incluídos no plano de cuidados, como tentativa de buscar a reinserção social desta família.

\section{REFERENCIAS}

Barreto, M. (2010). A construção do genograma na terapia de casal. Florianapolis:Monografia de especialização, Familiar e Instituto Sistêmico. Binotto, A.L., Santos, L.L., Lourosa, Q.L., Sant'Anna, S.C., Zanetti, A.C.G., Forster, A.C. y Marques, J.M.A. (2012). Interface Saúde da Família \& Saúde Mental: uma estratégia para o cuidado. Revista Brasileira de Medicina de Família e Comunidade, 7(23), 83-89.

Brasil. Ministério da Saúde. Secretaria de Atenção à Saúde. Departamento da Atenção Básica (2013). Caderno 34 - Saúde Mental na Atenção Básica. Brasília: Ministério da Saúde.

Brasil. Ministério da Saúde. Secretaria de Atenção à Saúde. Departamento da Atenção Básica. Coordenação Geral de Atenção Domiciliar (2012). Caderno de Atenção Domiciliar. Brasília: Ministério da Saúde.

Carnut, L. y Faquim, J. (2014). Conceitos de família e a tipologia familiar: aspectos teóricos para o trabalho da equipe de saúde bucal na 
estratégia de saúde da família. Journal of Management \& Primary Health Care, 5(1), 6270. Recuperado

http://www.jmphc.com.br/saudepublica/index.php/jmphc/article/view/198/201 Carvalho, J.C. (2015). A família e as pessoas com experiências de doença mental. Revista Portuguesa de Enfermagem de Saúde Mental (14). Editorial.

Correia, V.R., Barros, S.B. y Colvero, L.A. (2011). Saúde mental na atenção básica: prática da equipe de saúde da família. Revista da Escola de Enfermagem da Universidade de São Paulo, 45(6), 1501-6. Recuperado de http://www.scielo.br/pdf/reeusp/v45n6/v45n6a3 2.pdf

Costa, F.A.O. y Marra, M.M. (2013). Famílias brasileiras chefiadas por mulheres pobres e monoparentalidade feminina: risco e proteção. Revista Brasileira de Psicodrama, São Paulo, 21(1). Recuperado de http://pepsic.bvsalud.org/scielo.php?script=sci_a rttext\&pid=S0104-53932013000100011

Ditterich, R.G., Gabardo, M.C.L. y Moysés, S.J. (2009). As ferramentas de trabalho com famílias utilizadas pelas equipes de saúde da família de Curitiba, PR. Revista Saúde e Sociedade, São Paulo, 18(3), 515-524.

Dutra, E.M., Vasconcelos, E.E., Teófilo, J.K. y Teófilo, L.J.S. (2012). Atenção Integral aplicada à família: relato de experiência. SANARE: Revista de Políticas Públicas, Sobral, 11(1)1, 55-59.

Menezes, A.H.R., Cardelli, A.A.M. Vieira, G.B., Martins, J.T., Fernandes, M.V. y Marrero, T. (2012). Classificação do risco familiar segundo escala de Coelho e Savassi - um relato de experiência. Revista Ciência, Cuidado e Saúde, 11(1), 190-195.

Nascimento, K.V., Ximenes Neto, F.R.G., Saburido, K.A.L. y Chagas, M.I.O. (2012). Aplicação do Modelo Calgary na avaliação familiar de um sujeito com hipertensão arterial sistêmica. Revista Paraninfo Digital, 16, 1-13.

Savassi, L.C.M., Lage, J.L. y Coelho, F.L.G. (2012). Sistematização de um instrumento de estratificação de risco familiar: escala de risco familiar Coelho-Savassi. Journal of Management and Primary Health Care, 3(2), 179-185.

Silveira Filho, A.D., Ducci, L., Simão, M.G., Moysés, S.J. y Gevared, S.P. (2002). Os dizeres da boca em Curitiba: boca maldita, boqueirão, bocas saudáveis. Secretaria Municipal de Saúde de Curitiba. Centro Brasileiro de Estudos de Saúde: Rio de Janeiro, 155-160. Recuperado de http://bvsms.saude.gov.br/bvs/publicacoes/livro_ curitiba.pdf

Oliveira, E.N., Eloia, S.M.C., Lima, D.S., Eloia, S.C., Felix, T.A. y Vasconcelos, M.I.O. (2014).
A família no cuidado à pessoa com transtorno mental: uma revisão integrativa. Revista Tendências da Enfermagem Profissional, (6), 1196 -1202.

Santos, K.K.F., Figueiredo, C.R., Paiva, K.M., Campolina, L.R., Barbosa, A.A.D. y Santos, A.S.F. (2015). Ferramentas de abordagem familiar: uma experiência do cuidado multiprofissional no âmbito da Estratégia Saúde da Família. Revista da Universidade Vale do Rio Verde, Três Corações, 13(2), 377-387.

Santos, M.L.V.A. (2012). Abordagem sistémica do cuidado à família: impacto no desempenho profissional do enfermeiro. Tese de doutoramento, Universidade de Lisboa, Lisboa, Portugal.

Spagnuolo, R.S. y Guerrini, I.A. (2005). A construção de um modelo de Saúde complexo e transdisciplinar. Revista Interface Comunicação, Saúde e Educação, Botucatu, 9(16), 191-194.

Vieira, M.R.M., Ferreira, M.A.A., Araújo, C.A.S., Vieira, M.M. y Rodrigues, C.A.Q. (2014, setembro). Genograma e Ecomapa na Abordagem Familiar: um relato de caso em família com estrutura frágil e idoso dependente. Resumo expandido em anais do $8^{\circ}$ Fórum de Ensino Pesquisa Extensão e Gestão, Unimontes, Montes Claros, Minas Gerais. Recuperado de http://www.fepeg2014.unimontes.br/sites/default /files/resumos/arquivo_pdf_anais/genograma_e_ ecomapa_na_abordagem_familiar.pdf

Yin, R. (2001, p. 26). Estudo de caso: planejamento e métodos. Trad. Daniel Grassi $\left(2^{\mathrm{a}}\right.$ ed). Porto Alegre: Bookman. 